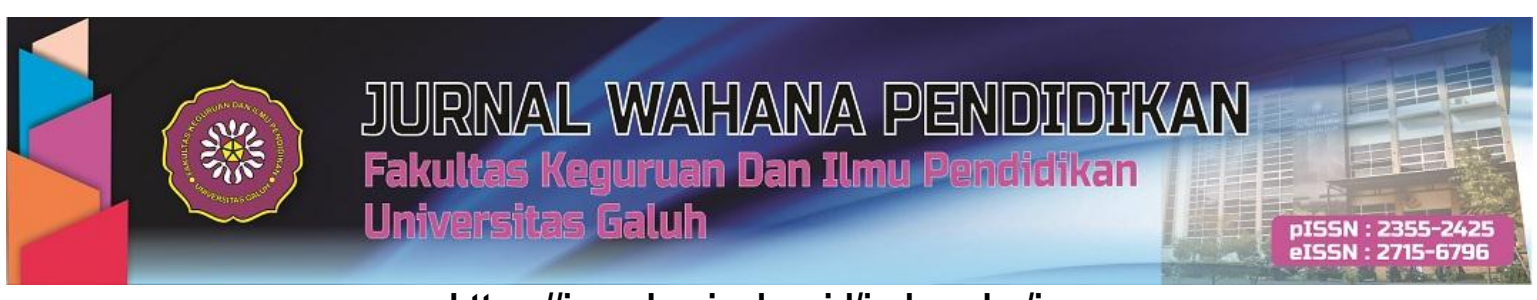

https://jurnal.unigal.ac.id/index.php/jwp

\title{
ANALISIS KONDISI FISIK PEMAIN SPARTAN BASKETBALL CLUB
}

\author{
Hendra Rustiawan ${ }^{1}$, Argian Rizki Taufik², Adang Sudrazat ${ }^{3}$ \\ 1 Universitas Galuh, Jl. R. E. Martadinata No.150, Ciamis, Indonesia \\ 2 Universitas Subang, Jl. R.A. Kartini Km 3 Subang, Indonesia \\ 3Universitas Pendidikan Indonesia, Kampus Sumedang Jl. Mayor Abdurahman No.211, Indonesia \\ Email: hendra6610111972@gmail.com
}

\begin{abstract}
The purpose of this study was to determine the actual physical condition of all Spartan Basketball Cimahi Club players. This type of research was quantitative descriptive. The research method was a survey method used was test and measurement techniques. The population used was the Spartan Basketball Cimahi Club, amounting to 24 mens, age range between 16-19 years. The instrument test used were consisted of a vertical jump, a 20 meter run, an illinois agility run test, eye, hand and foot coordination, and a bleep test. The statistical analysis used was descriptive statistics with a percentage system. The results of this study that the average physical condition of basketball players who were members of the Spartan Basketball Cimahi Club was moderate, meaning that this research was the actual data that exists in basketball players. Suggestions in this study to achieve achievement at a higher level one of the supporters was a change in physical condition by providing training programs that could be improved the appearance of the players in each basketball game.
\end{abstract}

Keywords: Basket ball, physical conditioning, spartan basketball club.

\section{ABSTRAK}

Tujuan dari penelitian ini adalah untuk mengetahui keadaan kondisi fisik yang sebenarnya seluruh pemain bola basket Spartan Basketball Cimahi Club. Jenis penelitian yang digunakan adalah deskriptif kuantitatif. Metode penelitiannya adalah metode survey dengan menggunakan teknik tes dan pengukuran. Populasi yang digunakan adalah Spartan Basketball Cimahi Club yang berjumlah 24 orang laki-laki, rentang usia antara 16-19 tahun. Instrument test yang digunakan terdiri dari vertical jump, lari 20 meter, ilinois agility run test, koordinasi mata, tangan, dan kaki, serta bleep test. Analisis statistika yang digunakan adalah statistika deskriptif dengan sistem prosentase. Hasil dari penelitian ini bahwa rata-rata kondisi fisik pemain bola basket yang tergabung dalam Spartan Basketball Cimahi Club adalah sedang, artinya penelitian ini sebagai data sebenarnya yang ada pada diri pemain bola basket. Saran dalam penelitian ini untuk mencapai prestasi pada jenjang yang lebih tinggi salah satu pendukung adalah adanya perubahan dalam kondisi fisik dengan pemberian program latihan yang mampu meningkatkan penampilan para pemain di setiap pertandingan bola basket.

Kata Kunci: Bola basket, Kondisi fisik, Spartan Basketball Cimahi Club

Cara sitasi:

Rustiawan, H., Taufik, A.R., \& Sudrazat, A. (2021). Analisis Kondisi Fisik Pemain Spartan Basketball Club. Jurnal Wahana Pendidikan, 8 (1), 01-14. 


\section{PENDAHULUAN}

Bola basket adalah salah satu olahraga yang digemari oleh kalangan masyarakat Indonesia baik di kota maupun di daerah, mulai dari kalangan anak-anak sekolah, mahasiswa maupun masyarakat umum. Ajang pertandingan bola basket ini selalu ada setiap tahun. Bahkan di setiap tingkatan sekolah maupun universitas memiliki jadwal rutin pertandingan bola basket setiap tahunnya, dengan berbagai tujuan yang beragam seperti untuk mencari atlet muda yang berbakat, promosi suatu lembaga pendidikan yang mengutamakan olahraga khususnya bola basket, atau para komunitas pencinta bola basket yang ingin mempertahankan bahkan lebih mempopulerkan dunia bola basket di suatu daerah. Hal ini memperlihatkan bahwa bola basket adalah olahraga kelompok yang mengandung unsur kesenangan, kepuasan, dan kerjasama tim para pemainnya (Darmawan et al., 2016). Tidak hanya itu bola basket juga menjadi salah satu keunggulan sekolah dalam meraih prestasi dan membantu dalam melanjutkan jenjang yang lebih tinggi melalui jalur prestasi olahraga (Islahuzzaman, 2010).

Bola basket termasuk olahraga permainan yang memiliki karakteristik khusus, terutama dalam peraturan pertandingan yang cukup ketat, namun hal tersebut tidak menurunkan antusias pencinta bola basket, bahkan sebaliknya semakin bertambah antusias ingin mencoba untuk menggeluti olahraga ini. Berbicara karakteristik permainan bola basket yang begitu menguras energi bagi pemainnya, karena banyak berlari, melompat, menjaga lawan, dan menyerang untuk satu tujuan yaitu menghasilkan poin dengan memasukan bola ke ring basket sebanyak mungkin (Solihin et al., 2016). Bahkan teori lain mengatakan bahwa terdapat dua faktor dalam bermain bola basket yang terdiri dari faktor internal dan eksternal. Faktor eksternal seperti teknik bermain bola basket, psikologis dari para pemain, motivasi dari masing-masing individu, dan yang terakhir adalah memiliki kondisi fisik yang baik. Faktor eksternal terdiri dari sarana dan prasarana pendukung, dan motivasi lingkungan sekitar (Prasetyo \& Sukarmin, 2017).

Penelitian ini akan membahas pada salah satu faktor internal yaitu kondisi fisik yang memang erat hubungannya dengan permainan bola basket yang menuntut kondisi fisik yang prima sesuai kebutuhan di lapangan seperti kekuatan, kecepatan, kelincahan, power, daya tahan, koordinasi, dan masih banyak lagi (Mashuri et al., 2019). Penampilan seorang pemain bola basket harus memiliki komponen kondisi fisik yang secara fisiologi olahraga adalah kemampuan seorang pemain bola basket yang dapat diketahui kemampuannya melalui permainan bola basket dan secara empiris dapat dilakukan dengan memberikan tes dan pengukuran sesuai kebutuhan pemain bola basket agar jelas diketahui tingkatan kondisi fisiknya (Wiwoho et al., 2014).

Berdasarkan pengamatan penulis dari beberapa pertandingan bola basket antar klub dilihat dari segi kondisi fisik sangat beragam sekali, artinya dari pertandingan satu ke pertandingan ke-dua atau lainnya menunjukan tingkat kondisi fisik naik dan turun secara individua. Beberapa pemain dalam satu pertandingan memiliki kondisi fisik yang baik dalam artian para pemain mampu menyelesaikan pertandingan dengan penampilan yang maksimal, namun dari beberapa pemain yang lain kondisi fisiknya terlihat kurang. Begitu pun sebaliknya ketika pertandingan berikutnya sebagian para pemain yang tadinya penampilan di lapangan terlihat kurang maksimal malah menjadi lebih baik, sedangkan para pemain yang di pertandingan yang lalu penampilannya maksimal, namun terlihat seperti kehabisan energi atau kurang maksimal. Hal ini menandakan bahwa tidak meratanya kondisi fisik yang dimiliki setiap pemain bola basket yang tergabung dalam Spartan Baskeball Cimahi Club.

Berbanding terbalik dengan beberapa pernyataan bahwa kondisi fisik yang prima dapat membantu terampilnya suatu teknik dan strategi serta meningkatkan mental para pemain dalam suatu pertandingan olahraga termasuk cabang olahraga bola basket (Anwar, 2013). Selain itu, kebutuhan pengetahuan ilmu olahraga yang selalu berkembang dan baru (sport science) menjadi salah satu kewajiban yang harus dimiliki oleh pelatih dalam membuat suatu program latihan yang akan diberikan kepada atletnya, dan jangan sampai program latihan yang diberikan tidak ada perubahan atau dengan kata lain menjenuhkan sehingga menurunkan motivasi berlatih. Untuk itu 
pelatih dan atlet harus senantiasa meng-upgrade keilmuan olahraganya yang disesuaikan dengan cabang olahraganya (Rohendi \& Rustiawan, 2020). Penelitian lain menyatakan bahwa memiliki kondisi fisik yang baik sangatlah bermanfaat baik terhadap penampilan di lapangan serta pada tubuh atletnya pun akan merasakan tubuh yang sehat, segar, dapat berpikir secara positif, memperlancar kerja jantung dan paru-paru, dan metabolisme tubuh yang baik (Rohendi et al., 2020). Bahkan ada juga yang mengatakan bahwa olahraga permainan yang menuntut pergerakan tubuh (mobilitas) yang sangat cepat dengan relatif waktu pertandingan yang cukup lama sehingga pemain harus memiliki daya tahan kardiovaskular yang cukup tinggi dengan performa yang tetap stabil mulai dari awal sampai akhir pertandingan (Rustiawan, 2020). Sehingga penulis menyimpulkan bahwa permainan bola basket merupakan cabang olahraga yang menuntut kondisi fisik yang baik dalam artian seluruh komponen kondisi fisik seperti kekuatan, kecepatan, power, koordinasi, aksi reaksi, kelincahan, keseimbangan dan daya tahan kardiovaskular harus bekerja secara maksimal yang dipadukan dengan unsur teknik sehingga terlihat penampilan pemain saat bertanding cukup maksimal terutama pelatih merasa puas melihat para pemain bekerja sesuai dengan strategi yang diterapkan ditambah dengan kemenangan di dalam suatu pertandingan.

Selanjutnya berdasarkan penelitian terdahulu tentang kondisi fisik pemain bola basket yang sangat beragam seperti pada penggunaan metode penelitian, pemilihan komponen kondisi fisik, partisipan yang digunakan, populasi, jumlah partisipan dan tingkatannya, jenis kelamin, usia dan masih banyak lagi. Namun penulis hanya membatasi pada bidang kondisi fisik yang dibutuhkan untuk cabang olahraga bola basket. Untuk itu beberapa yang akan di ungkap pada penelitian ini seperti penelitian yang hanya menerapakan 5 komponen kondisi fisik yaitu kekuatan, kecepatan, daya tahan, fleksibilitas, dan koordinasi. Serta menganggap bahwa 5 komponen kondisi fisik tersebut merupakan kondisi fisik dominan untuk bola basket (Mashuri et al., 2019). Penelitian lain menyebutkan ada 6 tes untuk mencari bakat pemain bola basket usia SD berumur 10-11 tahun yang terdiri dari verticall jump test, ball feeling test, wall pass test, shooting test, dribble test, shuttle run test. Tes ini merupakan perpaduan antara tes kondisi fisik dengan tes teknik bola basket (Iqroni, 2017). Namun ada juga penelitian yang mengarah khusus pada shooting three point yang dipadukan dengan kondisi fisik yaitu power dengan penggunaan jenis latihan pliometrik dengan kelincahan menggunakan alat bantu ladder, dan hasilnya adalah shooting three point pliometrik yang lebih signifikan (Taufik et al., 2020).

Ada juga penelitian untuk pemain bola basket putri se-kabupaten Gunung Kidul dengan memberikan 6 item tes komponen kondisi fisik yang terdiri dari tes daya tahan otot, kelincahan, kelentukan, kecepatan, keseimbangan, dan power tungkai (Pratama \& Sutopo, 2016). Penelitian yang terakhir untuk tes kondisi fisik pemain bola basket PPLOP Jawa Tengah menggunakan 7 item tes yang terdiri dari tes daya tahan anaerobik dengan sprint-fatigue test, kecepatan dengan tes sprint 60 meter, kekuatan dengan tes push-up dan sit-up, kelincahan dengan T-test, daya tahan aerobik dengan yo-yo test, kelentukan dengan $V$-sit and reach test, dan tes indeks masa tubuh (Syaukani et al., 2020).

Berdasarkan penjelasan dari beberapa penelitian yang terdahulu, terdapat perbedaan dengan penelitian penulis yang sekarang, karena dari penelitian yang lain tidak menggunakan tes daya tahan kardiovaskular untuk pemain bola basket, hanya satu penelitian yang menggunakan tes daya tahan aerobik yaitu yo-yo test sedangkan penulis menggunakan tes daya tahan kardiovaskular dengan Bleep test. Hal ini menunjukan adanya penggunaan tes daya tahan kardiovaskular yang bervariatif namun dengan tujuan yang sama untuk mengetahui kemampuan daya tahan kardiovaskular, dan penggunaan tes koordinasi mata, tangan, dan kaki yang sangat dibutuhkan dalam permainan bola basket seperti melakukan operan bola satu tangan dan dua tangan disertai dengan pergerakan kaki (footwork), dan dilanjutkan dengan penglihatan mata pun dituntut untuk dapat berkoordinasi antara menangkap bola dengan melempar bola tanpa terlepas dari ke-dua jarijari tangan. Hal ini memperlihatkan adanya penerapan alat ukur koordinasi mata, tangan, dan kaki pada penelitian ini yang sebelumnya belum ada pada penelitian yang terdahulu. Namun untuk tes 
yang lainnya seperti kekuatan, kecepatan, power, kelincahan, kelentukan, keseimbangan, dan masih banyak lagi adalah sesuatu yang sudah ada pada penelitian sebelumnya.

Berdasarkan latar belakang dan referensi penelitian yang terdahulu dengan berbagai penggunaan instrument test yang bervariatif dalam meningkatkan kondisi fisik pemain bola basket, yang memang merupakan faktor yang sangat penting untuk penampilan pemain bola basket terutama dalam pertandingan. Akhirnya penulis melakukan penelitian pada bidang kondisi fisik pemain bola basket dengan tujuan menganalisis kondisi fisik pemain bola basket Spartan Basketball Cimahi Club serta ingin mengetahui kondisi sebenarnya baik secara individu maupun secara keseluruhan, selain itu dapat dijadikan sebagai dasar bagi pelatih untuk dapat membuat program latihan yang baik dan benar serta tepat sasaran dalam meningkatkan kondisi fisik pemain bola basket.

\section{METODE PENELITIAN}

Jenis penelitian yang digunakan adalah deskriptif kuantitatif dengan menggunakan metode survey dan teknik yang digunakan adalah tes dan pengukuran komponen kondisi fisik. Pengertiannya bahwa pengambilan data di lapangan dilakukan secara sekaligus dengan pada suatu rentang tertentu yang sudah ditetapkan jadwal untuk melakukan pengambilan data di lapangan (Syaukani et al., 2020). Populasi penelitian adalah Spartan Basketball Cimahi Club. Partisipan yang terlibat berjumlah 24 pemain. Teknik pengambilan sampel yang digunakan adalah purposive sampling. Variabel yang akan diuji terdiri dari power, kecepatan, kelincahan, koordinasi, dan daya tahan kardiovaskular dengan instrument test yang dapat dilihat pada tabel 1.

\section{Tabel 1}

Instrumen penelitian kondisi fisik

\begin{tabular}{clll}
\hline No & \multicolumn{1}{c}{ Bentuk Tes } & \multicolumn{1}{c}{ Tujuan Tes } & \multicolumn{1}{c}{ Sumber } \\
\hline 1. & Tes Vertical Jump & Mengukur kemampuan power tungkai & (Impellizzeri et al., 2007) \\
2. & Tes lari 20 meter & Mengukur kemampuan kecepatan & (Castagna et al., 2008) \\
3. & llinois Agility Run Test & Mengukur kemampuan kelincahan & (Sheppard \& Young, 2006) \\
4. & Tes Koordinasi Mata, Tangan, Kaki & Mengukur kemampuan koordinasi & (Sridadi, 2010) \\
5. & Multi Stage Fitness Test (MSFT) & Mengukur daya tahan kardiovaskular & (Mackenzie, 2020) \\
\hline
\end{tabular}

Instrument test yang pertama adalah vertical jump test (Impellizzeri et al., 2007). Penulis beranggapan bahwa untuk mengukur lompatan pemain bola basket terutama dalam penerapan melakukan shooting three point shoot yang tidak hanya mengandalkan lengan saja, namun faktor lompatan saat mengerahkan power tungkai terutama ketika penjagaan lawan sangat rapat dengan pemain yang akan melakukan shooting three point yang berusaha melakukan lompatan tinggi agar bola tidak terganggu atau tidak direbut pemain lawan.

Instrument test yang ke-dua adalah tes lari 20 meter (Castagna et al., 2008). Penulis beranggapan bahwa pemain bola basket harus memiliki kecepatan berlari secara maksimal dengan tujuan agar pergerakan pemain dalam permainan bola basket mampu bereaksi secara cepat seperti pergerakan tanpa bola atau pergerakan melakukan shooting three point.

Instrument test yang ke-tiga adalah Illinois agility run test (Mackenzie, 2020). Alat ukur ini cocok untuk bola basket yang harus memiliki tingkat kelincahan yang cukup baik karena berdasarkan kebutuhan dalam permainan bola basket yang menuntut untuk melakukan pergerakan baik dengan bola maupun tanpa bola yang cepat dan jangan sampai kehilangan keseimbangan ketika merubah arah pergerakan tubuh.

Instrument test yang ke-empat adalah koordinasi mata, tangan, dan kaki (Sridadi, 2010). Pemain bola basket harus memiliki tingkat koordinasi yang baik dipadukan dengan pergerakan yang bervariatif serta cepat ketika melakukan dribbling, pandangan ke arah depan dengan melihat teman satu tim, yang harus dapat berlari dan melompat dengan melakukan shooting three point.

Instrument test yang ke-lima adalah tes daya tahan kardiovaskular penulis menggunakan Multi stage fitness test (MSFT) atau dengan kata lain multi fitness test (MFT) yang sama digunakan 
pada penelitian terhadap peningkatan vo2max pendaki atlet ekspedisi Soedirman VII (Festiawan et al., 2020).

Selanjutnya adalah analisis data dengan tujuan untuk mendeskripsikan hasil dari tes dan pengukuran dari ke-lima variabel. Analisis deskriptif data biasanya menggunakan perhitungan statistik analisis deskriptif prosentase (Anwar, 2013). Namun sebelumnya harus dicari dulu deskripsi data dari masing-masing tes kondisi fisik dengan tujuan agar diketahui secara umum seperti ratarata (mean), simpangan baku (standard deviasi), skor rendah dan skor tinggi. Hal tersebut akan dijelaskan secara lengkap pada bagian hasil dan pembahasan.

\section{HASIL DAN PEMBAHASAN}

Pembahasan pertama pada bagian ini adalah deskripsi dari lima tes kondisi fisik adalah sebagai berikut :

1. Vertical jump test dapat dilihat pada tabel 2.

Tabel 2

Skor Vertical Jump Test

\begin{tabular}{|c|c|c|c|c|}
\hline \multirow{2}{*}{ No } & \multirow{2}{*}{ Nama } & \multirow{2}{*}{$\begin{array}{c}\text { Tes } \\
\text { Vertical jump }\end{array}$} & \multicolumn{2}{|c|}{ Hasil Pengolahan Data } \\
\hline & & & Satuan & Kategori \\
\hline 1 & $A$ & 37 & $\mathrm{~cm}$ & Sangat kurang \\
\hline 2 & B & 55 & $\mathrm{~cm}$ & Baik sekali \\
\hline 3 & C & 50 & $\mathrm{~cm}$ & Baik sekali \\
\hline 4 & D & 50 & $\mathrm{~cm}$ & Baik sekali \\
\hline 5 & $\mathrm{E}$ & 49 & $\mathrm{~cm}$ & Baik \\
\hline 6 & $\mathrm{~F}$ & 49 & $\mathrm{~cm}$ & Baik \\
\hline 7 & G & 38 & $\mathrm{~cm}$ & Kurang \\
\hline 8 & $\mathrm{H}$ & 43 & $\mathrm{~cm}$ & Sedang \\
\hline 9 & I & 48 & $\mathrm{~cm}$ & Baik \\
\hline 10 & $\mathrm{~J}$ & 47 & $\mathrm{~cm}$ & Baik \\
\hline 11 & K & 56 & $\mathrm{~cm}$ & Baik sekali \\
\hline 12 & $\mathrm{~L}$ & 51 & $\mathrm{~cm}$ & Baik sekali \\
\hline 13 & $\bar{M}$ & 44 & $\mathrm{~cm}$ & Sedang \\
\hline 14 & $\mathrm{~N}$ & 48 & $\mathrm{~cm}$ & Baik \\
\hline 15 & 0 & 53 & $\mathrm{~cm}$ & Baik sekali \\
\hline 16 & $P$ & 49 & $\mathrm{~cm}$ & Baik \\
\hline 17 & $Q$ & 51 & $\mathrm{~cm}$ & Baik sekali \\
\hline 18 & $\mathrm{R}$ & 49 & $\mathrm{~cm}$ & Baik \\
\hline 19 & $S$ & 45 & $\mathrm{~cm}$ & Sedang \\
\hline 20 & $\mathrm{~T}$ & 56 & $\mathrm{~cm}$ & Baik sekali \\
\hline 21 & U & 45 & $\mathrm{~cm}$ & Sedang \\
\hline 22 & V & 43 & $\mathrm{~cm}$ & Sedang \\
\hline 23 & W & 41 & $\mathrm{~cm}$ & Kurang \\
\hline 24 & $x$ & 50 & $\mathrm{~cm}$ & Baik sekali \\
\hline
\end{tabular}

Tabel 3

Deskripsi Data tes Vertical Jump

\begin{tabular}{cccccc}
\hline & N & Rata-rata & Simpangan baku & Skor Terendah & Skor Tertinggi \\
\hline Lari 20 meter & 24 & 47.79 & 5.06 & 37 & 56 \\
\hline
\end{tabular}

Tabel 2 memperlihatkan data hasil tes vertical jump dari seluruh partisipan yang berjumlah 24 orang pemain bola basket Spartan Basketball Cimahi Club. Sedangkan pada tabel 3 memperlihatkan deskripsi data yang terdiri dari rata-rata dari seluruh pemain yang melakukan tes adalah $47.79 \mathrm{~cm}$ masuk pada kategori baik. Untuk simpangan baku adalah 5.06. Serta skor terendah adalah $37 \mathrm{~cm}$ sedangkan skor tertinggi adalah $56 \mathrm{~cm}$. Beragam skor yang didapat dengan kategori kurang, sedang, baik, dan baik sekali dapat dilihat pada distribusi frekuensi tes vertical jump pada tabel 4. 
Tabel 4

Distribusi Frekuensi Tes Vertical Jump

\begin{tabular}{ccccc}
\hline \multirow{2}{*}{ No } & \multirow{2}{*}{ Kelas Interval } & \multicolumn{2}{c}{ Frekuensi } & \multirow{2}{*}{ Kategori } \\
& & Absolut (Fa) & Relatif (\%) & \\
\hline 1 & $>50$ & 9 & $37.51 \%$ & Baik sekali \\
2 & $46>49$ & 7 & $29.16 \%$ & Baik \\
3 & $42>45$ & 5 & $20.83 \%$ & Sedang \\
4 & $38>41$ & 2 & $8.33 \%$ & Kurang \\
5 & $>37$ & 1 & $4.17 \%$ & Sangat kurang \\
& Jumlah & 24 & $100 \%$ & - \\
\hline
\end{tabular}

Berdasarkan tabel 4 tes vertical jump pemain Spartan Basketball Cimahi Club dengan kategori baik sekali ada 9 (sembilan) orang dengan nilai $>50$. Kategori baik ada 7 (tujuh) orang dengan rentangan nilai $46-49$. Kategori sedang ada 5 (lima) orang dengan rentangan nilai $42-45$. Kategori kurang ada 2 (dua) orang dengan rentangan nilai 38 - 41. Kategori sangat kurang ada 1 (satu) orang dengan rentang $>37$. Penjelasan dalam bentuk diagram dapat dilihat dibawah ini :

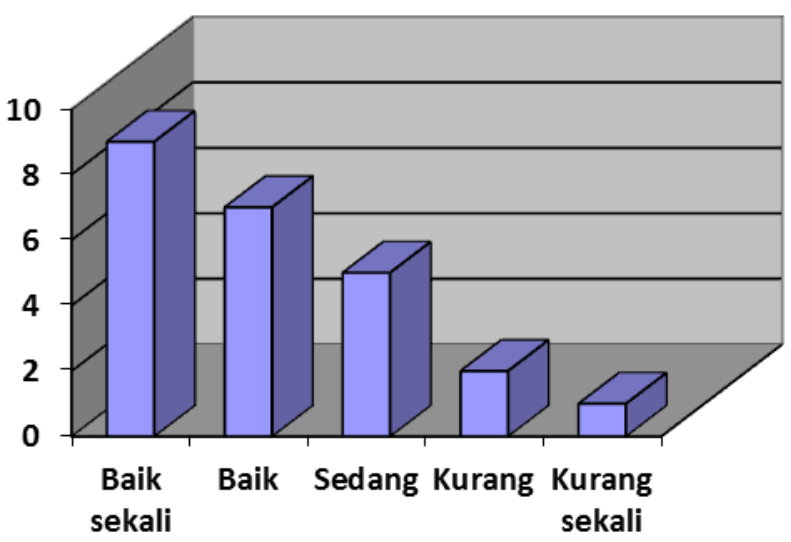

Diagram 1 Hasil Tes Vertical Jump Spartan Basketball Cimahi Club

Berdasarkan pada diagram 1 pemain bola basket Spartan Basketball Cimahi Club masuk pada kategori baik karena berdasarkan rata-rata yaitu $47.79 \mathrm{~cm}$. Hal ini menandakan bahwa kemampuan lompatan vertical jump pemain sudah cukup baik dan dapat dipertahankan bahkan ditingkatkan dan ini merupakan catatan bagi pelatih dalam membuat program latihan yang mampu membuat program latihan terutama untuk power tungkai dan jenis latihannya adalah pliometrik.

2. Tes lari 20 meter dapat dilihat pada tabel 5.

Tabel 5

Skor Lari 20 Meter

\begin{tabular}{ccccc}
\multicolumn{5}{c}{ Skor Lari 20 Meter } \\
\hline \multirow{2}{*}{ No } & Nama & $\begin{array}{c}\text { Tes } \\
\text { Lari 20 meter }\end{array}$ & $\begin{array}{c}\text { Hasil Pengolahan Data } \\
\text { Satuan }\end{array}$ & Kategori \\
\hline 1 & A & 7.15 & detik & Kurang \\
2 & B & 7.00 & detik & Sedang \\
3 & C & 6.00 & detik & Baik sekali \\
4 & D & 6.07 & detik & Baik \\
5 & E & 7.13 & detik & Kurang \\
6 & F & 6.47 & detik & Baik \\
7 & G & 7.05 & detik & Kurang \\
8 & H & 7.00 & detik & Sedang \\
9 & I & 6.94 & detik & Sedang \\
10 & J & 7.08 & detik & Kurang \\
11 & K & 7.08 & detik & Kurang \\
12 & L & 6.25 & detik & Baik \\
13 & M & 6.47 & detik & Baik \\
14 & N & 6.91 & detik & Sedang
\end{tabular}




\begin{tabular}{|c|c|c|c|c|c|c|}
\hline & & & & & & \\
\hline & 15 & 0 & 6.75 & detik & Sedang & \\
\hline & 16 & $P$ & 6.63 & detik & Sedang & \\
\hline & 17 & $Q$ & 6.62 & detik & Sedang & \\
\hline & 18 & $\mathrm{R}$ & 6.15 & detik & Baik & \\
\hline & 19 & $S$ & 7.04 & detik & Kurang & \\
\hline & 20 & $\mathrm{~T}$ & 6.89 & detik & Sedang & \\
\hline & 21 & $U$ & 6.95 & detik & Sedang & \\
\hline & 22 & V & 7.15 & detik & Kurang & \\
\hline & 23 & W & 6.91 & detik & Sedang & \\
\hline & 24 & $X$ & 7.08 & detik & Kurang & \\
\hline & & Des & psi Has & 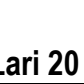 & Meter & \\
\hline & $\mathbf{N}$ & Rata-rata & Simpe & aku & Skor Terendah & Skor Tertinggi \\
\hline Lari 20 meter & 24 & 6.78 & & & 6.00 & 7.15 \\
\hline
\end{tabular}

Tabel 5 memperlihatkan data hasil tes lari 20 meter dan deskripsi data dari seluruh partisipan yang berjumlah 24 orang pemain bola basket Spartan Basketball Cimahi Club. Sedangkan pada tabel 6 memperlihatkan rata-rata dari seluruh pemain yang melakukan tes adalah 6.78 detik masuk pada kategori sedang. Untuk simpangan baku adalah 3.63. Serta waktu yang tercepat adalah 6.00 detik sedangkan waktu terlama adalah 7.15 detik Beragam skor yang didapat dengan kategori kurang, sedang, baik, dan baik sekali dapat dilihat pada distribusi frekuensi tes lari 20 meter pada tabel 7.

Tabel 7

Distribusi Frekuensi Tes Lari 20 Meter

\begin{tabular}{ccccc}
\hline \multirow{2}{*}{ No } & \multirow{2}{*}{ Kelas Interval } & \multicolumn{2}{c}{ Frekuensi } & \multirow{2}{*}{ Kategori } \\
& & Absolut (Fa) & Relatif (\%) & \\
\hline 1 & $>6.00$ & 1 & $4.17 \%$ & Baik sekali \\
2 & $6.01-6.50$ & 5 & $20.84 \%$ & Baik \\
3 & $6.51-7.00$ & 10 & $41.66 \%$ & Sedang \\
4 & $7.01 .-7.50$ & 8 & $33.33 \%$ & Kurang \\
5 & $>7.51$ & & $0 \%$ & Sangat kurang \\
& Jumlah & 24 & $100 \%$ & - \\
\hline
\end{tabular}

Berdasarkan tabel 7 tes lari 20 meter pemain Spartan Basketball Cimahi Club dengan kategori baik sekali ada 1 (satu) orang dengan nilai $>6.00$. Kategori baik ada 5 (lima) orang dengan rentangan nilai $6.01-6.50$. Kategori sedang ada 10 (sepuluh) orang dengan rentangan nilai $6.51-$ 7.00. Kategori kurang ada 8 (delapan) orang dengan rentangan nilai $7.01-7.50$. Kategori sangat kurang tidak ada. Penjelasan dalam bentuk diagram dapat dilihat dibawah ini :

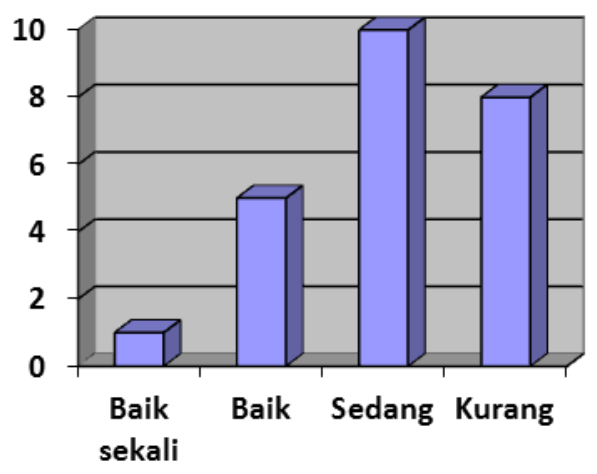

Diagram 2 Hasil Tes Lari 20 Meter Spartan Basketball Cimahi Club

Berdasarkan pada diagram 2 pemain bola basket Spartan Basketball Cimahi Club masuk pada kategori sedang karena berdasarkan rata-rata yaitu 6.78 detik. Hal ini menandakan bahwa 
kemampuan lari cepat pemain masih harus ditingkatkan dan ini merupakan catatan bagi pelatih dalam membuat program latihan yang sesuai kebutuhan pemain bola basket yang termasuk pada bidang kondisi fisik kecepatan lari.

3. Ilinois agility run test dapat dilihat pada tabel 8.

Tabel 8

Skor llinois Agility run test

\begin{tabular}{ccccc}
\hline No & Nama & $\begin{array}{c}\text { Tes } \\
\text { Vertical } \\
\text { jump }\end{array}$ & $\begin{array}{c}\text { Hasil Pengolahan Data } \\
\text { Satuan }\end{array}$ & Kategori \\
\hline 1 & A & 19.05 & detik & Baik sekali \\
2 & B & 18.81 & detik & Baik \\
3 & C & 17.93 & detik & Sedang \\
4 & D & 17.72 & detik & Sedang \\
5 & E & 19.01 & detik & Baik sekali \\
6 & F & 17.18 & detik & Sedang \\
7 & G & 18.16 & detik & Baik \\
8 & H & 19.03 & detik & Baik sekali \\
9 & I & 18.62 & detik & Baik \\
10 & J & 19.01 & detik & Baik sekali \\
11 & K & 19.00 & detik & Baik \\
12 & L & 16.66 & detik & Kurang \\
13 & M & 16.97 & detik & Kurang \\
14 & N & 18.00 & detik & Baik \\
15 & O & 17.47 & detik & Sedang \\
16 & P & 18.44 & detik & Baik \\
17 & Q & 17.63 & detik & Sedang \\
18 & R & 17.16 & detik & Sedang \\
19 & S & 18.15 & detik & Baik \\
20 & T & 17.05 & detik & Sedang \\
21 & U & 17.13 & detik & Sedang \\
22 & V & 18.16 & detik & Baik \\
23 & W & 17.07 & detik & Sedang \\
24 & X & 18.23 & detik & Baik \\
\hline & & & & \\
\hline
\end{tabular}

Tabel 9

Deskripsi Hasil Ilinois agility run test

\begin{tabular}{cccccc}
\hline & N & Rata-rata & Simpangan baku & Skor Terendah & Skor Tertinggi \\
\hline Agility & 24 & 17.98 & 7.75 & 16.66 & 19.05 \\
\hline
\end{tabular}

Tabel 8 memperlihatkan data hasil tes ilinois agility run test dan deskripsi data dari seluruh partisipan yang berjumlah 24 orang pemain bola basket Spartan Basketball Cimahi Club. Sedangkan pada tabel 9 memperlihatkan rata-rata dari seluruh pemain yang melakukan tes adalah 17.98 detik masuk pada kategori sedang. Untuk simpangan baku adalah 7.75. Serta skor yang terendah adalah 16.66 detik sedangkan skor tertinggi adalah 19.05 detik. Beragam skor yang didapat dengan kategori kurang, sedang, baik, dan baik sekali. Dapat dilihat pada distribusi frekuensi ilinois agility run test pada tabel 10.

Tabel 10

Distribusi Frekuensi Vertical Jump

\begin{tabular}{ccccc}
\hline \multirow{2}{*}{ No } & \multirow{2}{*}{ Kelas Interval } & \multicolumn{2}{c}{ Frekuensi } & \multirow{2}{*}{ Kategori } \\
& & Absolut (Fa) & Relatif (\%) & \\
\hline 1 & $>19.01$ & 5 & $20.83 \%$ & Baik sekali \\
2 & $18.01-19.00$ & 9 & $37.51 \%$ & Baik \\
3 & $17.01-18.00$ & 8 & $33.33 \%$ & Sedang \\
4 & $16.00-17.00$ & 2 & $8.33 \%$ & Kurang \\
5 & $<16.00$ & 0 & $0 \%$ & Sangat kurang \\
& Jumlah & 24 & $100 \%$ & - \\
\hline
\end{tabular}


Berdasarkan tabel 10 ilinois agility run test pemain Spartan Basketball Cimahi Club dengan kategori baik sekali ada 5 (lima) orang dengan nilai > 19.01. Kategori baik ada 9 (sembilan) orang dengan rentangan nilai 18.01 - 19.00. Kategori sedang ada 8 (delapan) orang dengan rentangan nilai 17.01 - 17.00. Kategori kurang ada 2 (dua) orang dengan rentangan nilai $16.00-17.00$. Kategori sangat kurang tidak ada. Penjelasan dalam bentuk diagram dapat dilihat dibawah ini :

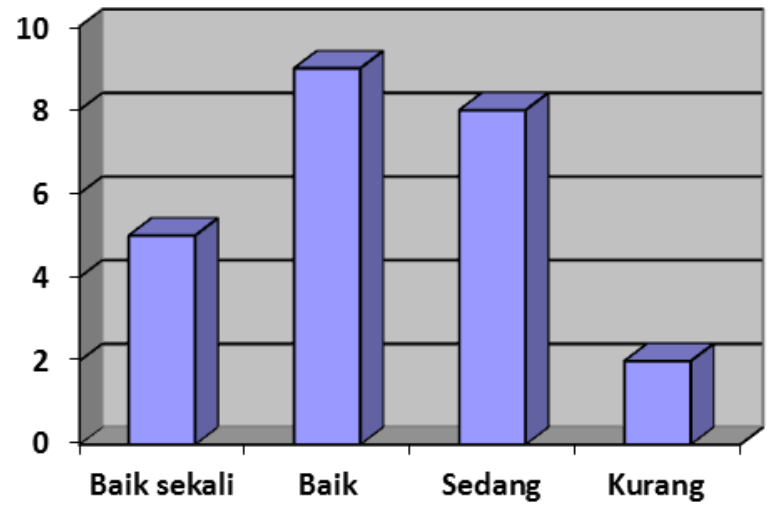

\section{Diagram 3 Hasil Ilinois Agility Run Test Spartan Basketball Cimahi Club}

Berdasarkan pada diagram 3 pemain bola basket Spartan Basketball Cimahi Club masuk pada kategori sedang. Hal ini menandakan bahwa kemampuan kelincahan masih harus ditingkatkan dan sesuai dengan data empiris yaitu berdasarkan pengamatan penulis di lapangan penampilan saat pertandingan tidak stabil.

4. Tes koordinasi mata tangan dan kaki dapat dilihat pada tabel 11.

Tabel 11

Skor Koordinasi Mata Tangan dan Kaki

\begin{tabular}{ccccc}
\hline No & Nama & $\begin{array}{c}\text { Tes } \\
\text { Koordinasi M T K }\end{array}$ & \multicolumn{2}{c}{ Hasil Pengolahan Data } \\
Satuan & Kategori \\
\hline 1 & A & 35 & detik & Baik \\
2 & B & 25 & detik & Kurang \\
3 & C & 22 & detik & Kurang \\
4 & D & 38 & detik & Baik \\
5 & E & 20 & detik & Kurang \\
6 & F & 23 & detik & Kurang \\
7 & G & 26 & detik & Sedang \\
8 & H & 17 & detik & Sangat kurang \\
9 & I & 36 & detik & Baik \\
10 & J & 27 & detik & Sedang \\
11 & K & 23 & detik & Kurang \\
12 & L & 45 & detik & Baik sekali \\
13 & M & 21 & detik & Kurang \\
14 & N & 19 & detik & Kurang \\
15 & O & 33 & detik & Sedang \\
16 & P & 42 & detik & Baik sekali \\
17 & Q & 37 & detik & Baik \\
18 & R & 27 & detik & Sedang \\
19 & S & 20 & detik & Kurang \\
20 & T & 30 & detik & Sedang \\
21 & U & 22 & detik & Kurang \\
22 & V & 25 & detik & Kurang \\
23 & W & 30 & detik & Sedang \\
24 & X & 27 & detik & Sedang \\
\hline & & & & \\
\hline
\end{tabular}


Tabel 12

Deskripsi Hasil Tes Koordinasi Mata Tangan dan Kaki

\begin{tabular}{cccccc}
\hline & N & Rata-rata & Simpangan baku & Skor Terendah & Skor Tertinggi \\
\hline Koordinasi & 24 & 27.91 & 7.62 & 17 & 45 \\
\hline
\end{tabular}

Tabel 11 memperlihatkan data hasil tes koordinasi mata tangan dan kaki dari seluruh partisipan yang berjumlah 24 orang pemain bola basket Spartan Basketball Cimahi Club. Sedangkan pada tabel 12 memperlihatkan rata-rata dari seluruh pemain yang melakukan tes koordinasi mata tangan dan kaki adalah 27.91 detik masuk pada kategori sedang. Untuk simpangan baku adalah 7.62. Serta skor yang terendah adalah 17 , sedangkan skor tertinggi adalah 45 . Beragam skor yang didapat dengan kategori kurang, sedang, baik, dan baik sekali dapat dilihat pada distribusi frekuensi tes koordinasi mata tangan dan kaki lari pada tabel 13.

Tabel 13

Distribusi Frekuensi Tes Koordinasi Mata Tangan dan Kaki

\begin{tabular}{ccccc}
\hline \multirow{2}{*}{ No } & \multirow{2}{*}{ Kelas Interval } & \multicolumn{2}{c}{ Frekuensi } & \multirow{2}{*}{ Kategori } \\
& & Absolut (Fa) & Relatif (\%) & \\
\hline 1 & $>42$ & 2 & $8.33 \%$ & Baik sekali \\
2 & $34-41$ & 4 & $16.67 \%$ & Baik \\
3 & $26-33$ & 7 & $29.16 \%$ & Sedang \\
4 & $18-25$ & 10 & $41.67 \%$ & Kurang \\
5 & $>17$ & 1 & $4.17 \%$ & Sangat kurang \\
& Jumlah & 24 & $100 \%$ & - \\
\hline
\end{tabular}

Berdasarkan tabel 13 tes koordinasi mata tangan dan kaki pemain Spartan Basketball Cimahi Club dengan kategori baik sekali ada 2 (dua) orang dengan nilai $>42$. Kategori baik ada 4 (empat) orang dengan rentangan nilai $34-41$. Kategori sedang ada 7 (tujuh) orang dengan rentangan nilai 26 - 33. Kategori kurang ada 10 (sepuluh) orang dengan rentangan nilai $18-25$. Kategori sangat kurang ada 1 (satu) dengan nilai > 17. Penjelasan dalam bentuk diagram dapat dilihat dibawah ini :

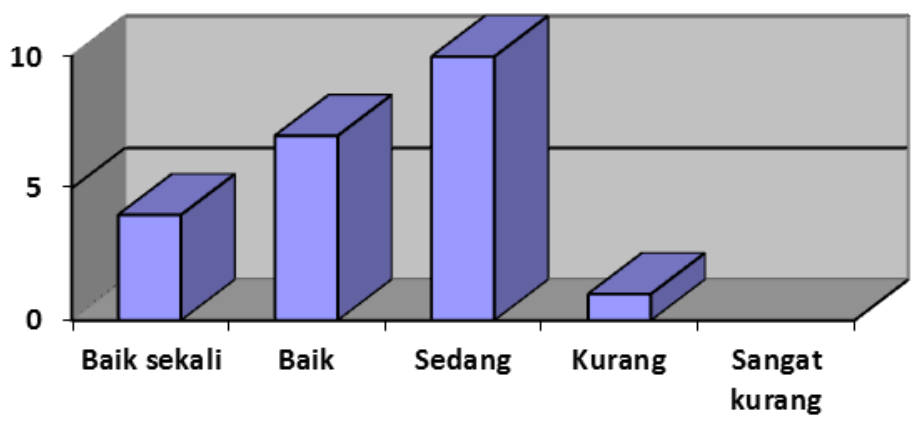

Diagram 4 Hasil Tes Lari 20 Meter Spartan Basketball Cimahi Club

Berdasarkan pada diagram 4 pemain bola basket Spartan Basketball Cimahi Club masuk pada kategori sedang karena berdasarkan rata-rata yaitu 27.91. Hal ini menandakan bahwa kemampuan koordinasi mata tangan dan kaki masih perlu ditingkatkan dan ini merupakan catatan bagi pelatih dalam membuat program latihan pada komponen kondisi fisik koordinasi.

5. Bleep test dapat dilihat pada tabel 14.

Tabel 14

Skor Bleep Test

\begin{tabular}{ccccc}
\hline \multirow{2}{*}{ No } & \multirow{2}{*}{ Nama } & \multirow{2}{*}{ Bleep Test } & \multicolumn{2}{c}{ Hasil Pengolahan Data } \\
& & & Satuan & Kategori \\
\hline 1 & A & 28.7 & $\mathrm{Ml} / \mathrm{k} / \mathrm{mnt}$ & Kurang \\
2 & $\mathrm{~B}$ & 27.2 & $\mathrm{Ml} / \mathrm{k} / \mathrm{mnt}$ & Kurang
\end{tabular}




\begin{tabular}{|c|c|c|c|c|}
\hline 3 & C & 31.8 & $\mathrm{Ml} / \mathrm{kl} / \mathrm{mnt}$ & Kurang \\
\hline 4 & D & 46.5 & $\mathrm{Ml} / \mathrm{kl} / \mathrm{mnt}$ & Baik \\
\hline 5 & $E$ & 46.8 & $\mathrm{Ml} / \mathrm{kl} / \mathrm{mnt}$ & Baik \\
\hline 6 & $\mathrm{~F}$ & 50.5 & $\mathrm{Ml} / \mathrm{kl} / \mathrm{mnt}$ & Baik sekali \\
\hline 7 & $G$ & 51.4 & $\mathrm{Ml} / \mathrm{kl} / \mathrm{mnt}$ & Baik sekali \\
\hline 8 & $\mathrm{H}$ & 35.0 & $\mathrm{Ml} / \mathrm{kl} / \mathrm{mnt}$ & Sedang \\
\hline 9 & I & 50.5 & $\mathrm{Ml} / \mathrm{kl} / \mathrm{mnt}$ & Baik sekali \\
\hline 10 & $J$ & 28.0 & $\mathrm{Ml} / \mathrm{kl} / \mathrm{mnt}$ & Kurang \\
\hline 11 & K & 27.6 & $\mathrm{Ml} / \mathrm{kl} / \mathrm{mnt}$ & Kurang \\
\hline 12 & $L$ & 26.8 & $\mathrm{Ml} / \mathrm{kl} / \mathrm{mnt}$ & Sangat kurang \\
\hline 13 & M & 40.5 & $\mathrm{Ml} / \mathrm{kl} / \mathrm{mnt}$ & Sedang \\
\hline 14 & $\mathrm{~N}$ & 46.8 & $\mathrm{Ml} / \mathrm{kl} / \mathrm{mnt}$ & Baik \\
\hline 15 & 0 & 44.2 & $\mathrm{Ml} / \mathrm{kl} / \mathrm{mnt}$ & Baik \\
\hline 16 & $P$ & 31.5 & $\mathrm{Ml} / \mathrm{kl} / \mathrm{mnt}$ & Kurang \\
\hline 17 & $Q$ & 31.8 & $\mathrm{Ml} / \mathrm{kl} / \mathrm{mnt}$ & Kurang \\
\hline 18 & $\mathrm{R}$ & 31.4 & $\mathrm{Ml} / \mathrm{kl} / \mathrm{mnt}$ & Kurang \\
\hline 19 & $S$ & 45.8 & $\mathrm{Ml} / \mathrm{kl} / \mathrm{mnt}$ & Baik \\
\hline 20 & $\mathrm{~T}$ & 40.5 & $\mathrm{Ml} / \mathrm{kl} / \mathrm{mnt}$ & Sedang \\
\hline 21 & U & 52.2 & $\mathrm{Ml} / \mathrm{kl} / \mathrm{mnt}$ & Baik sekali \\
\hline 22 & V & 48.7 & $\mathrm{Ml} / \mathrm{kl} / \mathrm{mnt}$ & Baik sekali \\
\hline 23 & W & 46.2 & $\mathrm{Ml} / \mathrm{kl} / \mathrm{mnt}$ & Baik \\
\hline 24 & $X$ & 39.9 & $\mathrm{Ml} / \mathrm{kl} / \mathrm{mnt}$ & Sedang \\
\hline
\end{tabular}

Tabel 15

Deskripsi Hasil Bleep Test

\begin{tabular}{cccccc}
\hline & N & Rata-rata & Simpangan baku & Skor Terendah & Skor Tertinggi \\
\hline Vo2max & 24 & 39.5 & 90.05 & 26.8 & 52.2
\end{tabular}

Tabel 14 memperlihatkan data hasil bleep test dari seluruh partisipan yang berjumlah 24 orang pemain bola basket Spartan Basketball Cimahi Club. Sedangkan pada tabel 15 memperlihatkan rata-rata dari seluruh pemain yang melakukan bleep test adalah $39.5 \mathrm{ml} / \mathrm{kg} / \mathrm{mnt}$ masuk pada kategori sedang. Untuk simpangan baku adalah 90.05. Serta skor yang terendah adalah $26.8 \mathrm{ml} / \mathrm{kg} / \mathrm{mnt}$, sedangkan skor tertinggi adalah $52.2 \mathrm{ml} / \mathrm{kg} / \mathrm{mnt}$. Beragam skor yang didapat dengan kategori kurang, sedang, baik, dan baik sekali dapat dilihat pada distribusi frekuensi bleep test pada tabel 16.

Tabel 16

Distribusi Frekuensi Bleep Test

\begin{tabular}{ccccc}
\hline \multirow{2}{*}{ No } & \multirow{2}{*}{ Kelas Interval } & \multicolumn{2}{c}{ Frekuensi } & \multirow{2}{*}{ Kategori } \\
& & Absolut (Fa) & Relatif (\%) & \\
\hline 1 & $>48$ & 5 & $20.83 \%$ & Baik sekali \\
2 & $41-47$ & 6 & $25 \%$ & Baik \\
3 & $34-40$ & 4 & $16.67 \%$ & Sedang \\
4 & $27-33$ & 8 & $33.33 \%$ & Kurang \\
5 & $<26$ & 1 & $4.17 \%$ & Sangat kurang \\
& Jumlah & 24 & $100 \%$ & - \\
\hline
\end{tabular}

Berdasarkan tabel 16 bleep test pemain Spartan Basketball Cimahi Club dengan kategori baik sekali ada 5 (lima) orang dengan nilai di atas $>48$. Kategori baik ada 6 (enam) orang dengan rentangan nilai 41 - 47. Kategori sedang ada 4 (empat) orang dengan rentangan nilai $34-40$. Kategori kurang ada 8 (delapan) orang dengan rentangan nilai 27 - 33. Kategori sangat kurang ada 1 (satu) dengan nilai di atas $>26$. Penjelasan dalam bentuk diagram dapat dilihat dibawah ini : 


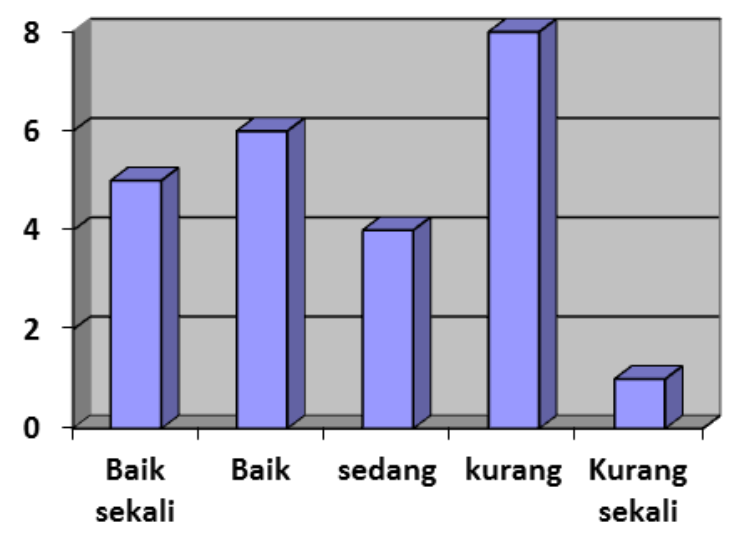

Diagram 5 Hasil Bleep Test Spartan Basketball Cimahi Club

Berdasarkan pada diagram 5 pemain bola basket Spartan Basketball Cimahi Club masuk pada kategori sedang karena berdasarkan rata-rata yaitu 39.5. Hal ini menandakan bahwa kemampuan Vo2max masih perlu ditingkatkan dan ini merupakan catatan bagi pelatih dalam membuat program latihan pada komponen kondisi fisik daya tahan kardiovaskular.

\section{KESIMPULAN}

Berdasarkan ke-lima tes kondisi fisik untuk pemain bola basket pada Spartan Basketball Cimahi Club yang terdiri dari tes vertical jump, tes lari 20 meter, tes kelincahan, tes koordinasi mata tangan dan kaki, serta tes vo2max rata-rata masuk pada kategori sedang bahkan cenderung kurang. Hal ini memperlihatkan bahwa seluruh pemain bola basket yang berjumlah 24 orang memiliki tingkat kemampuan kondisi fisik dari lima variabel komponen kondisi fisik yang terdiri dari power tungkai, kecepatan berlari, kelincahan, koordinasi, dan yang terakhir adalah kemampuan suplai oksigen pada daya tahan kardiovaskular masih perlu ditingkatkan.

Tim pelatih bola basket yang tergabung dalam Spartan Basketball Cimahi Club dengan mengetahui data penelitian ini tidak boleh tinggal diam, bahkan sebaliknya, harus merencanakan program latihan dengan sebaik-baiknya, seperti merubah atau membuat program latihan kondisi fisik yang baru dengan cara antara lain meng-upgrade pengetahuan semua tim pelatih dengan mengikuti pelatihan/penataran pelatih fisik yang terbaru, mendatangkan pakar pelatih kondisi fisik khusus untuk cabang olahraga bola basket, serta membiasakan untuk membaca dari berbagai sumber atau referensi yang terbaru seperti artikel penelitian yang sesuai dengan bidang kondisi fisik.

Diharapkan penelitian ini menjadi salah satu pertimbangan untuk Spartan Basketball Cimahi Club khususnya dan dunia olahraga bola basket di tanah air pada umumnya teruma dalam peningkatan komponen kondisi fisik para pemain bola basket.

\section{REKOMENDASI}

Berdasarkan hasil penelitian bahwa kategori yang didapat masuk pada kategori sedang bahkan cenderung kurang sehingga hasil penelitian ini dapat dijadikan tolak ukur untuk pelatih agar pembuatan program latihan kondisi fisik harus tepat sasaran dan sesuai dengan kebutuhan pemain bolabasket Spartan Basketball Cimahi Club.

\section{UCAPAN TERIMAKASIH}

Penulis mengucapkan terima kasih kepada pihak Spartan Basketball Cimahi Club dalam hal ini adalah pemilik sekaligus pelatih kepala yang telah memberikan izin dalam kelancaran proses pelaksanaan penelitian ini. 


\section{DAFTAR PUSTAKA}

Anwar, S. (2013). Survei Teknik Dasar Dan Kondisi Fisik Pada Siswa Sekolah Sepak Bola (Ssb) Se Kabupaten Demak Tahun 2012. Journal of Physical Education, Sport, Health and Recreation, 2(9), 596-604. https://doi.org/10.15294/active.v2i9.1861

Castagna, C., Impellizzeri, F. M., Rampinini, E., D'Ottavio, S., \& Manzi, V. (2008). The Yo-Yo intermittent recovery test in basketball players. Journal of Science and Medicine in Sport, 11(1), 202-208. https://doi.org/10.1016/j.jsams.2007.02.013

Darmawan, A. B., Januarto, O. B., \& Wahyud, U. (2016). Pengembangan Model Latihan Kombinasi Dribbling , Passing Dan Shooting Peserta Ekstrakurikuler Bolabasket di SMP Negeri 2 Kota Malang. Pendidikan Jasmani, 26(02), 351-364.

Festiawan, R., Suharjana, S., Priyambada, G., \& Febrianta, Y. (2020). High-intensity interval training dan fartlek training: Pengaruhnya terhadap tingkat VO2 Max. Jurnal Keolahragaan, 8(1), 9-20. https://doi.org/https://doi.org/10.21831/jk.v8i1.31076 This

Impellizzeri, F. M., Rampinini, E., Maffiuletti, N., \& Marcora, S. M. (2007). A vertical jump force test for assessing bilateral strength asymmetry in athletes. Medicine and Science in Sports and Exercise, 39(11), 2044-2050. https://doi.org/10.1249/mss.0b013e31814fb55c

Iqroni, D. (2017). Model tes keterampilan dasar dan kondisi fisik untuk mengidentifikasi bakat calon atlet bolabasket. Jurnal Keolahragaan, 5(2), 142-150. https://doi.org/10.21831/jk.v5i2.15595

Islahuzzaman, N. (2010). Identifikasi Bakat Usia Dini Siswa SD-SMP Surakarta. Paedagogy, 13(1), $61-69$.

Mackenzie, B. (2020). 101 Performance Evaluation tests (B. Mackenzie (ed.); First). jonathan.pye@electricwordplc.com.

Mashuri, H., Zawawi, M. A., Kholis, M. N., Junaidi, S., Budiman Agung Pratama, S. H., \& Jatmiko. (2019). Pelatihan Kondisi Fisik Dominan Bola Basket. JPPNu (Jurnal Pengabdian Dan Pemberdayaan Nusantara), 1(2), 42-47.

Prasetyo, D. W., \& Sukarmin, Y. (2017). Pengembangan Model Permainan untuk Pembelajaran Teknik Dasar Bola Basket di SMP. Jurnal Keolahragaan, 5(1), 12-23.

Pratama, C. Y., \& Sutopo, P. (2016). Kontribusi fisik dan teknik terhadap keterampilan dribbling atlet bolabasket putri junior Kabupaten Gunungkidul. Jurnal Keolahragaan, 4(2), 155-163. https://doi.org/10.21831/jk.v4i2.8885

Rohendi, A., \& Rustiawan, H. (2020). Kebutuhan Sport Science Pada Bidang Olahraga Prestasi. Journal Respecs, 2(1), 1-16.

Rohendi, A., Rustiawan, H., Rustandi, E., \& Sudrazat, A. (2020). Perbandingan Latihan Pass and Drill Circle dengan Pass and Follow Drill Square terhadap Peningkatan Passing Pendek pada Cabang Olahraga Sepakbola. Jurnal Kepelatihan Olahraga, Universitas Pendidikan Indonesia, 12(1), 31-38. https://ejournal.upi.edu/index.php/JKO/article/viewFile/24011/11678 
Rustiawan, H. (2020). Pengaruh Latihan Interval Training dengan Running Circuit Terhadap PeningkatanVo2 Max. Jurnal Wahana Pendidikan, 7(1), 15-28.

Sheppard, J., \& Young, W. (2006). Agility literature review: Classifications, training and testing. Journal of Sports Sciences, 24(9), 919-932. https://doi.org/10.1080/02640410500457109

Solihin, A., Yusup, U., Satriya, \& Kusumah, W. (2016). Pengaruh Latihan 40-yard Ladder Sprint dan Latihan Zig-Zag Run Terhadap Peningkatan Kelincahan Siswa Pada Cabang OLahraga Bolabasket. Jurnal Kepelatihan Olahraga, 8(2), 70-85.

Sridadi. (2010). Sumbangan Tes Koordinasi Mata, Tangan, dan Kaki yang Digunakan Untuk Seleksi Calon Mahasiswa Baru Prodi PJKR Terhadap Mata Kuliah Praktek Dasar Gerak SOFTBALL. Pendidikan Jasmani Kesehatan Dan Rekreasi.

Syaukani, A. A., Subekti, N., \& Sudarmanto, E. (2020). Tingkat Kondisi Fisik Atlet Bolabasket PPLOP Jawa Tengah Ditentukan dengan Tes dan Pengukuran Khusus. JUARA: Jurnal Olahraga, 5(1), 66-74. https://doi.org/10.33222/juara.v5i1.779

Taufik, A. R., Ma'mun, A., \& Mulyana. (2020). Dampak Shooting Three Point Plyometric dan Ladder Terhadap Hasil Shooting Three Point Bola Basket. Gelanggang Olahraga: Jurnal Pendidikan Jasmani Dan Olahraga, 3(2), 197-212. https://doi.org/https://doi.org/10.31539/jpjo.v3i2.1302

Wiwoho, H. A., Junaidi, S., \& Sugiarto. (2014). Profil Kondisi Fisik Siswa Ekstrakurikuler Bola Basket Putra Sma N 02 Ungaran Tahun 2012. Journal of Sport Sciences and Fitness, 3(1), 44-48. 